
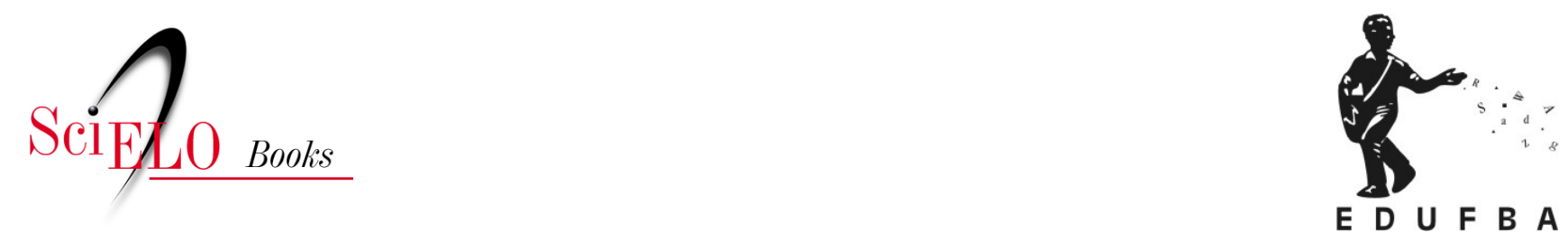

\title{
Mudanças climáticas e aspectos relacionados com o estado da Bahia
}

\author{
Tania Mascarenhas Tavares \\ Sérgio Telles de Oliva \\ Rodolfo Rojas Guarín \\ Carolina L. Wilches Arciniegas
}

\section{SciELO Books / SciELO Livros / SciELO Libros}

TAVARES, T.M., OLIVA, S.T., GUARÍN, R.R., and ARCINIEGAS, C.L.W. Mudanças climáticas e aspectos relacionados com o estado da Bahia. In: FERNANDES, R.C.P., LIMA, M.A.G., and ARAÚJO, T.M., comps. Tópicos em saúde, ambiente e trabalho: um olhar ampliado [online]. Salvador: EDUFBA, 2014, pp. 271-290. ISBN: 978-65-5630-012-2. https://doi.org/10.7476/9786556300122.0014.

All the contents of this work, except where otherwise noted, is licensed under a Creative Commons Attribution 4.0 International license.

Todo o conteúdo deste trabalho, exceto quando houver ressalva, é publicado sob a licença Creative Commons Atribição 4.0. 


\title{
Mudanças climáticas e aspectos relacionados com o estado da Bahia
}

\author{
Tania Mascarenhas Tavares \\ Sérgio Telles de Oliva \\ Rodolfo Rojas Guarín \\ Carolina L. Wilches Arciniegas
}

\section{Introdução}

O estado da Bahia, assim como os demais estados brasileiros, está relacionado às mudanças climáticas sob dois aspectos: a sua contribuição em termos de gases estufa para a atmosfera do planeta e os efeitos que sofrerá com as mudanças climáticas. Vamos analisar as duas situações separadamente.

\section{Impactos previstos para o estado da Bahia decorrentes das previsões de mudanças climáticas}

Ao longo da sua vida, a terra já vivenciou várias mudanças climáticas causadas por fenômenos naturais. Essas mudanças eram geralmente gradativas, em escala de tempo geológica de séculos, milênios e milhões de anos. (GRAEDEL; CRUTZEN, 1995, BAILEY et al., 2002)

No momento existe uma previsão - endossada pela ONU e por cientistas de um grande número de países do mundo -, que a temperatura média da terra irá aumentar num curto prazo de tempo geológico, menos de um século, em decorrência das emissões de gases estufa lançadas pelas atividades antrópicas. Prevê-se, também, um aumento das faixas de variações das temperaturas, ou seja, verões serão mais quentes e os invernos mais frios. (IPCC, 2007) O quarto relatório do Painel Internacional de Mudanças Climáticas, publicado em 2007 - 
o IPCC AR4 (2007) - é o maior e mais detalhado sumário da situação de mudanças climáticas já elaborado, tendo sido produzido por milhares de autores, editores e revisores de dezenas de países citando mais de 6 mil estudos científicos revisados.

Processos naturais podem se somar, compensar ou anular o aquecimento global decorrente do aumento dos gases estufas na atmosfera. A intensificação da atividade solar pode ser responsável por parte do aumento da temperatura do planeta observada nas últimas décadas. (SCAFETTA, 2010) As erupções vulcânicas, a depender de sua natureza, podem baixar a temperatura da terra durante o período no qual as partículas emitidas se mantiverem em suspensão na atmosfera. (GRAEDEL; CRUTZEN, 1995) Recentemente alguns astrônomos têm apresentado cálculos correlacionando os períodos orbitais de Júpiter e Saturno e o ciclo solilunar, com as variações de temperatura do planeta numa escala temporal de 20-60 anos e atribuindo pelo menos $60 \%$ do aquecimento observado, desde 1970, como tendo sido induzido por essas oscilações, inclusive com a previsão de uma possível estabilização ou resfriamento até 2030-2040. (SCAFETTA, 2010) Outras oscilações astronômicas estão sendo correlacionadas com variações na formação de nuvens altas, e consequentemente da reflexão da radiação incidente sobre a terra, resultando na variação de temperatura da sua superfície. Essas oscilações resultariam da variação das órbitas dos cometas em relação ao sol, com emissão maior ou menor de poeira cósmica (STOZHKOV et al., 2007) e das modulações da ionosfera (SCAFETTA, 2012). Essas últimas entraram na fase do ciclo de 60 anos favorável ao aumento da reflexão de radiação, portanto na fase de resfriamento da terra, prevendo-se uma possível estabilidade ou decréscimo da temperatura da terra nas próximas décadas (SCAFETTA, 2012).

A própria poluição atmosférica, emitida na forma de partículas, pode ter efeitos opostos em relação à temperatura, a depender do tamanho e da composição das partículas. Os efeitos podem ser diretos ou indiretos. Nos efeitos diretos, as partículas suspensas no ar absorvem radiação aquecendo o local onde estão presentes, como é o caso da fuligem. Uma parcela do aquecimento da temperatura em centros urbanos decorre das emissões de partículas veiculares e não apenas do aumento da concentração dos gases estufa. (GRAEDEL; CRUTZEN, 1995) Estudos recentes atribuem cerca de $70 \%$ do aquecimento nas 
montanhas do Himalaia, resultantes da presença de partículas de fuligem em suspensão e as principais responsáveis pelo derretimento das geleiras, ao invés do aquecimento global dos gases estufa. (SRIVASTAVA et al., 2012) Como efeitos indiretos temos as partículas de poluição do ar se concentrando em determinadas alturas da atmosfera, formando verdadeiras nuvens de material particulado que impedem a radiação solar de alcançar a superfície da terra e, portanto, causando um resfriamento. Outro efeito indireto é a indução de formação de nuvens devido ao aumento de núcleos de condensação de gotículas e partículas geladas que as compõem, aumentando a reflexão da radiação solar incidente. (IPCC, 2007)

Certamente esses aspectos publicados nos últimos cinco anos serão incorporados no próximo relatório a ser publicado em 2014, o IPCC AR5. É possível que as previsões atuais sejam revistas. Adotamos nessa avaliação dos impactos previstos para o estado da Bahia as previsões do último relatório publicado pelo IPCC, com o qual o Governo Brasileiro se alinha através do Ministério do Meio Ambiente (MMA) e do Instituto Nacional de Pesquisas Espaciais (INPE). Sugere-se que a presente avaliação seja revista em 2014, após o lançamento do próximo relatório.

De acordo com o IPCC AR4 (2007), o Brasil é vulnerável às mudanças climáticas. As mudanças climáticas principais serão o aumento de temperatura média do ar - consequentemente, do solo e das águas - e o aumento da faixa de variação das temperaturas - consequentemente, dos desastres naturais. Já existem evidências de mudanças climáticas no Brasil, mas as mudanças serão maiores e mais evidentes a partir de 2030, não só no nosso país, mas também em todo o planeta.

Os estudos mostram que, no Brasil, a temperatura média aumentou aproximadamente $0,75^{\circ} \mathrm{C}$ até o final do século 20 (considerando a média anual entre $1961-90$ de $24,9^{\circ} \mathrm{C}$ ). Em nível regional, é possível observar que, no período de 1951-2002, as temperaturas mínimas cresceram em todo o país, apresentando um aumento expressivo de até $1,4^{\circ} \mathrm{C}$ por década. As tendências de aquecimento são detectadas em nível anual e sazonal, com maiores aquecimentos no inverno e na primavera. (MARENGO, 2007)

Existem projeções do aumento futuro das temperaturas para diferentes níveis de emissões de gases estufa no planeta. (IPCC, 2077) Mantendo-se a taxa de crescimento atual das emissões (Cenário A2), 
o nordeste brasileiro se tornará, em média, 2 a $4^{\circ} \mathrm{C}$ mais quente até o fim do presente século com redução no volume de chuva que pode exceder a $60 \%$. Se as emissões de gases estufa mundiais conseguirem ser reduzidas, num cenário de baixa emissão (B2), a temperatura do nordeste brasileiro aumentará 1 a $3^{\circ} \mathrm{C}$ com redução de até $60 \%$ do volume de chuva. As variações ao longo do Século XXI foram analisadas por Marengo (2007), examinando as previsões dos diversos modelos utilizados pelo IPCC e por outras instituições, resumindo as anomalias de temperatura, umidade e chuva do nordeste, para três faixas de tempo, 2010 a 2040, 2041 a 2071 e 2071 a 2100, e para dois cenários, B2 de baixas emissões e A2 de altas emissões de carbono. Marengo (2007) concluiu que o nordeste brasileiro tenderá a ser mais quente e o ar mais úmido - uma vez que a evaporação será mais intensa - e os solos mais secos, havendo um aumento nas anomalias de chuva durante os períodos chuvosos, que terão menor duração e os de estiagem que serão mais prolongados. No horizonte de 2050, o aquecimento previsto é de aproximadamente $1,6^{\circ} \mathrm{C}$ no cenário de emissões $\mathrm{B} 2$ e $2^{\circ} \mathrm{C}$ no cenário $\mathrm{A} 2$, enquanto as anomalias de chuva chegarão a $+0,4 \mathrm{~mm}$ por dia durante o período de chuvas, em ambos os cenários. No horizonte de 2080, o aquecimento previsto é de $2,5^{\circ} \mathrm{C}$ no cenário de baixas emissões (B2) e $3,5^{\circ} \mathrm{C}$ no cenário de altas emissões (A2), enquanto as anomalias de chuva podem chegar a $+0,5 \mathrm{~mm}$ por dia, nos dois cenários. Marengo (2007) registra uma diferença entre as previsões de dois modelos matemáticos: o modeHadCM3, inglês, que prevê aumentos de temperatura mais altos $\left(2,5^{\circ} \mathrm{C}\right.$ para $\mathrm{B} 2$ e $3,5^{\circ} \mathrm{C}$ para $\left.\mathrm{A} 2\right)$ e o modelo CSIRO, da Austrália, que prevê aumentos de $2,1^{\circ} \mathrm{C}$ e $3,3^{\circ} \mathrm{C}$, respectivamente. Por outro lado, o modelo HadCM3 prevê poucas anomalias de chuva nos dois cenários, diferentemente do modelo CSIRO.

Dessa forma as previsões de Marengo (2007) apontam:

[...] para um clima de Nordeste mais quente e ligeiramente mais úmido. É de esperar que as altas temperaturas do ar podem gerar aumento da evaporação na região e assim o futuro pode ser caracterizado por uma redução do volume de água armazenada no solo e deficiência no balanço hidrológico, e que não seria compensada pelas anomalias positivas de chuva como simuladas pelos modelos. Assim, o problema de "aridização" do Nordeste no futuro poderia ser devido a um aumento nas taxas de evaporação e às altas temperaturas do ar. Isto pode ter consequências graves na atividade agrícola e irrigação. 
Em Dezembro de 2009, durante a 15a Conferência Anual de Mudanças Climáticas nas Nações Unidas, realizada na Dinamarca, o Centro Hadley de Meteorologia do Reino Unido, em parceria com o Instituto Nacional de Pesquisas Espaciais (INPE), apresentou um quadro mais sombrio sobre os impactos do aquecimento global no Brasil. De acordo com modelo construído com os dados das duas instituições, o aquecimento no Brasil poderá ser $20 \%$ maior que a média mundial durante o século XXI. Isso significa, por exemplo, que se o planeta tiver uma alta de $1,8{ }^{\circ} \mathrm{C}$ na temperatura, a resposta no Brasil será de $2^{\circ} \mathrm{C}$. Pode parecer pouco, mas é preciso lembrar que o planeta terra já se aqueceu $0,7^{\circ} \mathrm{C}$ nos últimos 50 anos e com muitas consequências maléficas identificadas e mensuradas. Os pesquisadores britânicos e brasileiros mostram, nesse estudo, que as chuvas seriam reduzidas em 15\% na Bacia do São Francisco.

Por outro lado, estudos recentes de calibração do modelo matemático desse mesmo Centro Hadley do Reino Unido, conduzidos pela Universidade Federal da Bahia (UFBA) (TANAJURA; GENZ; ARAÚJO, 2010), indicam que os resultados dos modelos estão mais altos do que os dados observados, e que a região sofreria um pouco menos do que o anunciado.

As modelagens matemáticas do IPCC preveem que as mudanças de valores médios de temperatura e chuva vêm acompanhadas de variações de amplitude mais altas, ou seja, que as temperaturas máximas e mínimas irão aumentar, ocorrendo ondas de calor e de frio, mais fortes, de chuvas mais intensas e períodos de estiagem mais longos (IPCC 2007). Portanto, o impacto das mudanças climáticas previsto é maior do que a simples observação das variações médias anuais.

O impacto possível dessas mudanças de clima, sobre o nordeste, foi assim sumarizado por Marengo do INPE, durante a III Conferência Regional sobre Mudanças Globais: América do Sul, 2007, em São Paulo.

Aumento das secas, especialmente no semiárido; Impactos na agricultura de subsistência e na saúde; Perda de biodiversidade da caatinga; Risco de desertificação; Possível migração para outras regiões (refugiados do clima); Chuvas intensas podem aumentar o risco de deslizamentos podendo afetar as populações que moram em morros desmatados; Enchentes urbanas mais intensas. (DIAS et al., 2007) 
Adicione-se a esse sumário os seguintes impactos adicionais descritos no IPCC (2007) e pelo próprio Marengo (2007) em relatórios do INPE:

- Possíveis prejuízos na produção da energia hidroelétrica, com aumento de chuvas intensas e estiagens;

- Aumento do nível do mar, danificando os recifes de corais e manguezais - além de inundar as áreas costeiras ocupadas -, afetando a produção pesqueira que, na região nordeste é muito dependente desses ecossistemas

- Aumento dos vetores epidemiológicos tropicais - portanto a saúde da população animal (ex. vírus desconhecidos) e humana (p. ex. aumento de dengue, de malária);

- Conflitos sociais, decorrentes da migração de populações.

- Possíveis ocorrências de furacões e tufões devido ao aumento da temperatura da superfície do mar (Emanuel, 2005) - como já vem ocorrendo no sul do Brasil nos últimos anos e divulgados amplamente pela mídia.

Para o estado da Bahia são previstos, entre os vários efeitos, dois principais: a elevação do nível do mar, afetando as macrorregiões litorâneas e a elevação da temperatura média com aumento da evapotranspiração, intensificando a aridez, afetando principalmente as regiões interioranas e continentais, ou seja, o Cerrado e o Semiárido.

Principais impactos nas macrorregiões litorâneas: Litoral norte, litoral sul e Recôncavo/RMS.

Devido a mudanças climáticas e evolução geológica, a feição da Baia de Todos os Santos mudou ao longo dos séculos. Há apenas 10.000 anos atrás podíamos andar a pé de Salvador até Itaparica, que não seria uma ilha, e sim uma área um pouco mais elevada. O rio Paraguaçu e outros riachos que deságuam na atual baia, já existiam muito antes dessa época e desaguavam diretamente no oceano. Durante os últimos 9.000 anos, sua forma e dimensões já mudaram muitas vezes. (MARTIN et al. 1979; LEITE, 1995; LEITE, 1997) 
A Baía de Todos os Santos faz parte da bacia sedimentar do Recôncavo e está implantada sobre rochas sedimentares. (BITTENCOURT BRICHTA; DI NAPOLI, 1976) Durante um determinado intervalo de tempo, um movimento descendente denominado subsidência, determinou a sua formação. Alguns estudos antigos e revistos recentemente atribuem a modelagem da baia principalmente a movimentos tectônicos recentes. (MARTIN et al., 1986; CIRANO; LESSA, 2007) Outros trabalhos foram além, levando em consideração as variações eustáticas do nível do mar durante o Cenozoico. (MARTIN; DOMINGUEZ; BITTENCOURT, 1998; MARTIN; DOMINGUEZ; BITTENCOURT, 2003) Considerando esse,

[...] o principal fator a determinar a origem e o modelado da Baía de Todos os Santos, que teria resultado da erosão diferencial associada a um dramático rebaixamento do nível de base. Tanto é assim que existe uma perfeita correlação entre a altitude do terreno e a resistência das diferentes unidades geológicas à erosão. (BITTENCOURT; BRICHATA; DI NAPOLI, 1976)

Esses processos ocorreram em escala geológica, onde a evolução era gradativa e não havia ocupação antrópica. Atualmente, o entorno da Baía de Todos os Santos está ocupado, praticamente na sua totalidade, com aglomerados urbanos e atividades produtivas - industriais e agropastoris - num tecido socioeconômico-ambiental estreitamente entrelaçado, onde mudanças ambientais afetam intensamente a organização social e a economia. Em menor intensidade, situação semelhante ocorre em grande parte do litoral de todo o Estado. Em todos os casos, as mudanças climáticas afetarão toda a zona litorânea baiana. O aumento médio da temperatura do oceano Atlântico entre 1961-1990 foi de $1{ }^{\circ} \mathrm{C}$, o que resultou em um aumento de volume das suas águas devido a expansão térmica - a partir de $4^{\circ} \mathrm{C}$ o volume por unidade de peso de água aumenta. (IPCC, 2007) Esse acontecimento vem sido atribuído aos avanços do mar em toda a costa brasileira nos últimos dez anos e amplamente divulgados pela televisão, particularmente no nordeste. No caso dessas macrorregiões baianas, as ilhas têm sido as maiores vítimas, principalmente as ilhas mais planas, onde as águas adentram facilmente, como Itaparica, na macrorregião Recôncavo/RMS, com o número maior de registros de avanço do mar na sua costa oceânica. No caso de Itaparica, a situação já é séria o suficiente para motivar a 
Prefeitura do Município de Vera Cruz - e que ocupa a maior parte da ilha - a solicitar verba específica ao Governo Estadual para construir uma proteção da parte de sua costa mais vulnerável. A elevação do nível do mar é a maior ameaça decorrente das mudanças climáticas. A partir do ano 2030, quando se espera um aumento de mais 1 ou $2^{\circ} \mathrm{C}$ de temperatura média, o nível do mar deverá subir mais rapidamente, inundando a parte mais baixa da costa continental e das ilhas, inclusive das cidades litorâneas, entre elas parte de Salvador. A depender do aumento que ocorra na temperatura, a inundação será maior ou menor. Em 2100 é de se supor que uma parte significativa da cidade do Salvador, assim como das cidades de Itaparica, Ilhéus, Caravelas, Porto Seguro, entre muitas outras que estão localizadas em áreas baixas, sejam parcialmente invadidas pelo mar. A falta de cartas hipsométricas com resolução mínima de $10 \mathrm{~cm}$ de cota da franja costeira do Estado, ou até mesmo da capital, Salvador, e de outras cidades litorâneas, impede a construção de um cenário mais preciso e detalhado dos efeitos das mudanças do clima no litoral baiano. Outros efeitos que já vem sendo observados em várias partes do mundo, devido à elevação da temperatura do mar, são os danos aos recifes de corais. A presença de recifes de corais é responsável por grande parte da produtividade pesqueira marinha tropical.

A riqueza de fauna marinha na costa brasileira depende, na sua maior parte, dos ecossistemas costeiros, principalmente manguezais e recifes de corais. Isso porque a corrente do Brasil, bordejando a nossa costa, é de águas quentes, portanto pobres em nutrientes e consequentemente em fauna piscosa. Nessa situação, é da maior importância a preservação desses ecossistemas costeiros para a manutenção da riqueza de fauna marinha baiana.

O aumento de temperatura da água, entre outros fatores, pode causar danos aos recifes de corais, inibindo o seu crescimento e danificando sua estrutura - é o fenômeno denominado de branqueamento dos recifes de corais. As colônias recifais branqueadas são susceptíveis à instalação de doenças infecciosas, ou mesmo à mortandade em massa. O branqueamento de corais já vem sendo observado nos recifes baianos desde 1993, - inclusive no Parque Nacional Marinho dos Abrolhos. (KRUG et al., 2012) Nos recifes da Bahia há uma forte relação entre o branqueamento de corais e os eventos de anomalias da temperatura da 
superfície do mar (TSM), e os recifes mais afetados pelo branqueamento são os recifes costeiros. (LEÃO; KIKUCHI; OLIVEIRA, 2008)

Simulações dos efeitos de aumento de temperatura podem ser feitas em função das variações de temperatura dos fenômenos cíclicos de "El Niño" e "La Niña". "La Niña" se caracteriza pelo resfriamento das águas na região do Pacífico Equatorial e pela convecção na região da Indonésia e o "El Niño" apresenta impactos climáticos opostos. Essa oscilação é conhecida como oscilação Sul do "El Niño" (ENSO) e previsões sobre o efeito do aumento de temperatura podem ser feitas estudando-se séries históricas de um fenômeno e correlacionando-se com as variações de oscilações de ENSO. Um estudo desse tipo mostrou que a elevação de temperatura correlaciona-se com a redução do crescimento de corais do estado da Bahia. (EVANGELISTA et al., 2007)

Portanto, um aumento de temperatura das águas do Atlântico deverão reduzir os recifes de coral, consequentemente a produtividade da fauna marinha e de pescados. Os pescados representam uma importante fonte de proteína para os baianos vivendo nas zonas costeiras e, para comunidades de pescadores artesanais, são essenciais.

\section{Principais impactos nas macrorregiões do cerrado e semiárido}

Com o aumento da temperatura, a evapotranspiração aumenta, causando uma diminuição da água do solo e levando a uma gradual substituição da vegetação natural do cerrado, com a atual vegetação da zona semiúmida, por espécies da zona semiárida, e a vegetação da zona semiárida sendo substituída pela vegetação escassa de zonas áridas. A previsão é de perda de $24 \%$ das espécies de árvores para um aumento de temperatura de $2^{\circ} \mathrm{C}$. Nas áreas mais secas a mudança climática deverá provocar salinização e desertificação de áreas hoje agriculturáveis devido ao aumento da evapotranspiração. (MARENGO, 2007)

A produtividade de algumas culturas agrícolas importantes deverá decrescer e a produtividade pecuária deverá declinar nessa região, a menos que espécies modificadas geneticamente para resistência a temperaturas mais altas e menor disponibilidade de água venham a ser desenvolvidas e aí utilizadas. Vale lembrar o número limitado de espécies 
naturais das zonas áridas, que não conseguem substituir a perda da biodiversidade natural das zonas semiáridas e da biomassa de sua vegetação. Além desse fato, existe indisponibilidade de um banco genético de espécies adaptadas a temperaturas médias mais altas do que as existentes, para sua substituição nas zonas áridas. Outro fator a ser considerado é que as mudanças no padrão de precipitação previstas, principalmente em relação à mudança de amplitude da variação aliada a evapotranspiração, deverão afetar a regularidade de disponibilidade hídrica e o potencial hidroelétrico. As previsões indicam que a produção agrícola deverá apresentar tendências negativas após 2025, devido à insuficiência do abastecimento de água para atender às demandas da água de irrigação. (MARENGO, 2007)

Com o aumento da temperatura, os vetores epidemiológicos deverão aumentar (IPCC, 2007). Sendo o nordeste uma região onde a proliferação de insetos é favorecida pelas altas temperaturas perenes, um aumento de temperatura só irá favorecer ainda mais a proliferação da malária, dengue, dentre outras doenças transmitidas por insetos.

Utilizando-se do fenômeno cíclico de "El Niño" e "La Niña", verificou-se que a taxa de incidência da dengue na região nordeste, correlaciona positivamente com a oscilação Sul do "El Niño" (ENOS), durante o período de 1995 e 2007, como indicação de cenários possíveis resultantes das mudanças climáticas futuras. (SANTOS et al., 2011)

Alguns países têm feito esforços de adaptação, particularmente através de conservação de ecossistemas importantes, gerenciamento de riscos na agricultura, estratégias para gerenciamento de seca, entre outros. Entretanto, a efetividade desses esforços é diminuída por falta de informações básicas e sistemas de observação e monitoramento detalhados, além de capacitação e referências políticas, institucionais e tecnológicas apropriadas. (LONDON CLIMATE CHAGE PARTNERSHIP, 2006; DIAS et al., 2009) O Brasil e o estado da Bahia devem aprender com essas experiências.

\section{Contribuição do estado da Bahia para as mudanças climáticas}

As emissões industriais, urbanas e agropastoris influenciam enormemente o clima do planeta, pois emitem diferentes gases para a 
atmosfera. Alguns desses gases têm a capacidade de absorver radiação infravermelha (calor), e quando presentes na baixa troposfera, absorvem o calor emitido, principalmente, pela superfície terrestre. São os Gases de Efeito Estufa, abreviadamente denominados de GEE.

Os principais gases estufa são o dióxido de carbono, ou gás carbônico $\left(\mathrm{CO}_{2}\right)$, emitido principalmente pela queima de combustível fóssil e de biomassa; o metano $\left(\mathrm{CH}_{4}\right), 20$ a 25 vezes mais potente como gás estufa do que o $\mathrm{CO}_{2}$ num período de 100 anos, proveniente da decomposição de matéria orgânica e da produção pastoril, sobretudo gado bovino; o ozônio troposférico, $\mathrm{O}_{3}$, resultado da reação química na atmosfera dos hidrocarbonetos com o dióxido de nitrogênio, $\mathrm{NO}_{2}$, provenientes das emissões da queima de combustível fóssil e biomassa, além de industriais; o óxido nitroso $\left(\mathrm{N}_{2} \mathrm{O}\right)$, com poder de aquecimento da temperatura atmosférica 300 vezes maior do que o $\mathrm{CO}_{2}$, emitido principalmente pelas atividades agropecuárias, sobretudo por solos fertilizados, além do vapor d'água, resultado da evaporação das águas superficiais (rios, lagos e oceanos) e da evapotranspiração do solo, plantas e animais. Atualmente o aumento das emissões de $\mathrm{CO}_{2}$ é responsável por $50 \%$ da elevação da temperatura do planeta. (GRAEDEL; CRUTZEN, 1995; BAILEY et al., 2002, IPCC, 2007)

O principal gás de estufa emitido pelas atividades urbanas e produção de energia é o dióxido de carbono, $\mathrm{CO}_{2}$. Na cidade, a maior fonte urbana de $\mathrm{CO}_{2}$ é a veicular. Diferentemente de um grande número de países desenvolvidos, que utilizam carvão ou derivados de petróleo para a geração de energia, a energia elétrica do Brasil é essencialmente hidroelétrica, que é de baixa emissão de $\mathrm{CO}_{2}$. No entanto a produção de energia termoelétrica vem crescendo nos últimos anos, e envolvendo maiores emissões de $\mathrm{CO}_{2}$ pelo setor. A maior fonte brasileira de emissão do gás carbônico tem origem na queima da biomassa, essencialmente das queimadas.

O Brasil já apresentou dois inventários de emissões nacionais dos principais gases estufa dentro da Convenção de Mudanças de Clima das Nações Unidas, sempre utilizando os valores de fluxos default do IPCC, que muitas vezes não refletem os fluxos reais no Brasil. (EMBRAPA, 2006)

Em 2010, a Secretaria do Meio Ambiente do Estado da Bahia, publicou o primeiro inventário de gases de efeito estufa do Estado, uti- 
lizando a metodologia do IPCC. O inventário não está disponível na internet e as informações que se seguem foram obtidas de divulgação no site da CETESB, SP.

Os cálculos foram feitos para duas épocas diferentes, 1999 e 2008. No entanto, não há alocação por macrorregião. Foram estimadas todas as emissões e remoções antrópicas relativas aos seguintes gases: dióxido de carbono $\left(\mathrm{CO}_{2}\right)$, o metano $\left(\mathrm{CH}_{4}\right)$ e o óxido nitroso $\left(\mathrm{N}_{2} \mathrm{O}\right)$. O Inventário inclui tanto as emissões decorrentes da queima de combustíveis, quanto às emissões fugitivas. Outros gases, como monóxido de carbono (CO), óxidos de nitrogênio (NOx) e outros compostos orgânicos voláteis não metânicos (NMVOC), mesmo não sendo gases de efeito estufa direto, influenciam as reações químicas que ocorrem na atmosfera. Por essa razão, as suas emissões foram incluídas.

As emissões de GEE do Setor Energético da Bahia em 2008 totalizaram $28.555 \mathrm{GgCO}_{2}$ eq, sendo o segmento energético o maior responsável pelas emissões, com $32 \%$ de participação, seguido dos segmentos de transporte e indústria com $30 \%$ e $20 \%$, respectivamente. Na comparação com 1990, observa-se um significativo crescimento nas emissões totais dos GEE, da ordem de $83 \%$, sendo que as emissões de $\mathrm{CO}_{2}$ tiveram a maior responsabilidade e cresceram $87 \%$ nesse período. Registra-se uma grande inversão nos segmentos mais emissores do setor de energia, uma vez que em 1990, de um total de 15.585 $\mathrm{GgCO}_{2}$ eq emitidos, o setor industrial respondeu por $37 \%$, enquanto que o setor energético amplo contribuiu com apenas $12 \%$. As maiores reduções relativas ocorreram no segmento de cimento, que a partir de 2001, praticamente zerou as suas emissões, no segmento de outros minerais não metálicos, que também apresentaram importante redução das emissões e na indústria química, cujas emissões decresceram 14\%. Considerando-se apenas as emissões do setor industrial, a produção de magnésio, cimento, ferro e aço e ferroligas foram os maiores responsáveis por emissões de $\mathrm{CO}_{2}$ em 2008.

Em janeiro de 2010, foi promulgada a Lei $n^{\circ} 12050 / 11$. Essa lei institui a Política sobre Mudança do Clima do Estado da Bahia com os objetivos que se seguem:

a. Compatibilização do desenvolvimento socioeconômico com a proteção do sistema climático; 
b. Mitigação dos impactos adversos resultantes das interferências antrópicas no sistema climático;

c. Redução da taxa de crescimento das emissões de gases de efeito estufa e a captura e estocagem desses gases;

d. Definição e implementação de medidas para promover a adaptação à mudança do clima em todos os Territórios de Identidade, setores econômicos e sociais, especialmente aqueles mais vulneráveis aos seus efeitos adversos.

Para que essa política seja corretamente implantada e um plano de gestão correto seja adotado, será necessário efetuar-se inventários específicos por macrorregião e por município, onde todas as contribuições da agricultura, produção animal, florestas, atividades industriais e atividades urbanas sejam calculadas. Nesse caso, os fatores de emissões locais deverão ser determinados, substituindo os fatores default do IPCC.

Com a adoção de biocombustíveis no Brasil, a Bahia apresenta um potencial de crescimento no setor de produção de oleaginosas para a produção de biodiesel. No momento somente a soja é economicamente viável para a produção de biodiesel, mas espera-se que avanços tecnológicos viabilizem economicamente o uso de mamona, dendê, girassol, algodão, entre outros. As culturas dessas oleaginosas são bem adaptadas à área do cerrado e do semiárido, portanto é de se esperar uma grande expansão agrícola de oleaginosas nessas macrorregiões. Em termos de mudanças climáticas, essa expansão agrícola deverá envolver maiores emissões de gases estufa, sobretudo de óxido nitroso $\left(\mathrm{N}_{2} \mathrm{O}\right)$, que é um gás de estufa muito potente. Essa perspectiva tem preocupado cientistas proeminentes dos países desenvolvidos como o prêmio Nobel Crutzen. (CRUTZEN et al., 2007)

Os primeiros estudos experimentais relacionados a emissões de gases estufa de plantações de oleaginosas, no estado da Bahia, vêm sendo realizados no Cerrado e em zona de transição do semiárido, já tendo gerado informações interessantes e importantes relatadas abaixo. 


\section{Contribuição do cerrado e semiárido baiano para as mudanças climáticas}

As mudanças de ocupação do solo influenciam enormemente o clima do planeta, pois atividades agropastoris assim como outras atividades antrópicas, emitem gases diferentes para a atmosfera. $\mathrm{O}$ principal gás de estufa emitido por plantas de sequeiro é o óxido nitroso $\left(\mathrm{N}_{2} \mathrm{O}\right)$, que é um gás com a capacidade de aquecimento da atmosfera 300 vezes maior do que o dióxido de carbono $\left(\mathrm{CO}_{2}\right)$. A produção animal, principalmente de gado bovino, é um grande emissor de metano $\left(\mathrm{CH}_{4}\right)$, cuja capacidade de aquecimento atmosférico é 20 a 25 vezes a do $\mathrm{CO}_{2}$ num período de 100 anos, além do óxido nitroso $\left(\mathrm{N}_{2} \mathrm{O}\right)$.

Em termos globais, as emissões de óxido nitroso $\left(\mathrm{N}_{2} \mathrm{O}\right)$ de plantações, contribui com $75 \%$ das emissões antrópicas para a atmosfera. No Brasil, cerca de $10 \%$ da produção de soja é destinada a produção de biodiesel. O governo brasileiro almeja tornar o país líder mundial na produção de biodiesel, prevendo uma grande expansão na produção de oleaginosas, principalmente no semiárido da região nordeste.

A aceitação do biodiesel brasileiro depende das vantagens em termos de emissões de gases estufa que sejam apresentadas. Existem poucos trabalhos de emissões de $\mathrm{N}_{2} \mathrm{O}$ no cerrado brasileiro e sempre focalizam as emissões de diferentes culturas e não em termos de substituição da flora natural pelas plantações. Os primeiros trabalhos desse tipo no cerrado e na zona de transição do semiárido baiano, são também os primeiros do país, com o enfoque de substituição de cobertura, medindo emissões do $\mathrm{N}_{2} \mathrm{O}$ com e sem cobertura de campos de soja, mamona e girassol, além das emissões do cerrado original, da Mata Atlântica e da cultura familiar de subsistência do aipim, estimando-se a contribuição da substituição de florestas originais pela cultura de soja e demais oleaginosas. (GUARÍN, 2010; ARCINIEGAS et al., 2012; TAVARES et al., 2012)

Com base nos dados produzidos experimentalmente de medidas no estado da Bahia, mamona e girassol no município de Cruz das Almas e soja no Cerrado, pode-se calcular as emissões de $\mathrm{N}_{2} \mathrm{O}$ e $\mathrm{CO}_{2}$ pelo estado da Bahia decorrentes da cultura dessas oleaginosas. (GUARÍN, 2010; ARCINIEGAS et al., 2012) 
Foi estimada a contribuição estadual anual e, para fins de comparação, estimou-se a contribuição nacional, expressa em $\mathrm{kg} \mathrm{N}_{2} \mathrm{O}$ ha $^{-1}$ ano $^{-1}$ e $\mathrm{CO}_{2}$-equivalente $\mathrm{ha}^{-1}$ ano $^{-1}$. Utilizaram-se como referência, os dados de áreas agrícolas do estado da Bahia e Brasil de 2008. (Tabela 1).

Tabela 1 - Estimativa das emissões de $\mathrm{N}_{2} \mathrm{O}$ expressas em $\mathrm{CO}_{2}$ - equivalente proveniente das culturas de oleaginosas - mamona e girassol - e de aipim produção familiar de sobrevivência - no estado da Bahia e no Brasil

\begin{tabular}{|c|c|c|c|c|c|c|c|}
\hline \multirow[b]{2}{*}{ Cultura } & \multirow{2}{*}{$\begin{array}{c}\text { Área } \\
\text { cultivada } \\
\text { (ha) }\end{array}$} & \multirow[b]{2}{*}{$\begin{array}{l}\text { Produção } \\
(\mathrm{t})\end{array}$} & \multirow[b]{2}{*}{$\begin{array}{l}\text { Produtividade } \\
\text { (kg/ha) }\end{array}$} & \multirow{2}{*}{$\begin{array}{l}\text { Biodiesel } \\
\text { (l/t mat. } \\
\text { prima) }\end{array}$} & \multicolumn{2}{|c|}{...Emissão } & \multirow{2}{*}{$\begin{array}{c}\mathrm{CO}_{2-}^{-} \\
\text {equivalente** } \\
\left(\mathrm{TgCO}_{2}-\mathrm{eq}\right)\end{array}$} \\
\hline & & & & & $\begin{array}{c}\mathrm{KgN}_{2} \mathrm{O} \mathrm{ha}^{-} \\
{ }^{1} \mathrm{ano}^{-1}\end{array}$ & $\begin{array}{c}\mathrm{Gg} \mathrm{N} \mathbf{N}_{2} \mathrm{O} \\
\text { ha }^{-1} \text { ano }^{-1}\end{array}$ & \\
\hline Mamona & & & & & 0,62 & $6,20 \times 10^{-7}$ & \\
\hline Bahia & 122879 & 98706 & 803 & $540-720$ & 76714,73 & 0,077 & 0,024 \\
\hline Brasil & 162700 & 123400 & 758 & & 101575,42 & 0,102 & 0,032 \\
\hline Girassol & & & & & 0,47 & $4,70 \times 10^{-7}$ & \\
\hline Bahia & 1240 & 999 & 806 & $400-672$ & 581,24 & 0,0006 & 0,0002 \\
\hline Brasil & 113900 & 156900 & 130 & & 53389,71 & 0,053 & 0,017 \\
\hline Aipim & & & & & 0,67 & $6,70 \times 10^{-7}$ & \\
\hline Bahia & 392055 & 275017 & 12950 & & 262206,38 & 0,262 & 0,081 \\
\hline Brasil & 1882500 & 26598600 & 14010 & & 1259016,00 & 1,259 & 0,390 \\
\hline $\begin{array}{l}\text { Rem.Mata } \\
\text { Atlântica }\end{array}$ & & & & & 0,92 & $9,20 \times 10^{-7}$ & \\
\hline Brasil & 4662500 & & & & 4288287,78 & 4,288 & 1,330 \\
\hline
\end{tabular}

Fonte: Cadernos NAE, (2005); Petrobras; Parente, Expedito José de Sá-Tecbio, Fortaleza, (2003) apud SEAGRI, (2006); EMBRAPA, (2008); Epagri - CEPA (2008); IBGE (2008); Secretaria de Ciência, Tecnologia e Inovação, (2009); Portela, (2010).

**Fonte: (GUARIN, 2010)

Em função das áreas plantadas na Bahia e território nacional e fatores de emissão determinados em Cruz das Almas, no ano base de 2008, observa-se que, dentre a contribuição das oleaginosas estudadas para a emissão de $\mathrm{N}_{2} \mathrm{O}$, o girassol é a plantação que menos emite $\mathrm{N}_{2} \mathrm{O}$. Quando se levou em consideração as diferentes emissões entre as fileiras plantadas e as entrelinhas, as diferentes taxas de emissão e respectivas durações de cada fase do plantio, as emissões durante a parte do ano sem cobertura entre a pós-colheita e a nova plantação, se comparou com as emissões de $\mathrm{N}_{2} \mathrm{O}$ da floresta natural de Mata Atlântica natural, 
verificou-se que a substituição pelas culturas de oleaginosas resultaram em redução de emissões de $\mathrm{N}_{2} \mathrm{O}$ : redução de $32 \%$, no caso da mamona e $49 \%$ no caso de girassol. A substituição da mata por cultura familiar de mandioca resultou também em redução da emissão desse gás estufa, no caso de $27 \%$. Ou seja, as taxas de emissão da Mata Atlântica superam as emissões de todas as culturas estudadas, conforme pode ser visto na Tabela 1.

Em estudo equivalente no cerrado baiano, focando a cultura de soja - hoje a principal fonte de biodiesel - realizado por Arciniegas e colaboradores (2012), chegou a conclusões similares. Foi verificado que a substituição da mata de cerrado pela soja resultou na redução de $41 \%$ das emissões de $\mathrm{N}_{2} \mathrm{O}$.

Em termos de contribuição para as mudanças climáticas, esse fato favorece a adoção do biodiesel, além da motivação original do uso do biodiesel envolvendo a reciclagem do $\mathrm{CO}_{2}$. Vale lembrar que essa perspectiva econômica só constituirá uma real vantagem para o país se os bancos genéticos do cerrado ocupado por soja e do semiárido por outras oleaginosas, forem preservados em áreas de conservação adequadas.

Esses dados são importantes não apenas para a aceitação do biodiesel. Constituem uma contribuição importante para cálculos mais exatos dos inventários de emissões nacionais, permitindo a substituição dos fatores de emissão default do IPCC, fatores de emissões médios dos diferentes ecossistemas terrestres por valores de fluxo medidos, e dessa forma permitindo um melhor planejamento econômico-ecológico para o Brasil.

\section{Considerações finais}

As projeções dos modelos climáticos apontam para um aquecimento global até o fim deste século e particularmente uma elevação na temperatura média do nordeste brasileiro. O estado da Bahia sofrerá com as mudanças climáticas previstas. As áreas baixas costeiro-marinhas serão inundadas devido à elevação do nível do oceano, devendo provocar prejuízos materiais e desorganização social, sobretudo nas áreas urbanas. A produção pesqueira será reduzida uma vez que os recifes de corais e manguezais serão afetados. As regiões do semiárido e do cerrado, que constituem cerca de $57 \%$ e $22 \%$ respectivamente, totalizan- 
do $79 \%$ do Estado, terão suas temperaturas médias aumentadas, com aumento mais pronunciado nos meses de verão, fevereiro e março, que é o mês chuvoso. O período de chuvas será reduzido e o período seco irá incrementar, aumentando as secas nordestinas. Com a elevação da temperatura média, a evapotranspiração irá aumentar, incrementando a umidade do ar, mas diminuindo a umidade do solo e reduzindo os recursos hídricos superficiais, inclusive os disponíveis para a irrigação. A salinização irá aumentar e áreas hoje agriculturáveis se tornarão desérticas. A biodiversidade será reduzida, a produtividade agrícola e pecuária decrescerá e haverá aumento de doenças transmitidas por insetos.

Os malefícios sofridos pelo estado da Bahia não devem corresponder à contribuição do Estado para o aumento dos gases estufa. Isso porque, a utilização de agrocombustível não só evita as emissões de dióxido de carbono, mas reduz também a emissão de dióxido de nitrogênio com a substituição das florestas nativas por culturas de oleaginosas.

A maior parte dos cenários climáticos é produzida por modelos matemáticos, os quais ainda podem ter problemas em representar realmente os processos físicos que acontecem na natureza. Além disso, esses modelos têm dificuldade para representar adequadamente características do clima regional, que é onde há interesse de se avaliar impactos ambientais, econômicos e sociais. Adicione-se a essas, as incertezas sobre os cenários futuros de emissões dos gases de efeito estufa para este século e a efetividade do uso de modelos climáticos globais como a melhor ferramenta para estimar-se alterações climáticas resultantes do aquecimento global.

Mesmo diante dessas incertezas, dados de medidas locais têm demonstrado que o clima está mudando e as mudanças observadas seguem as tendências desses cenários.

Por fim vale ressaltar que as projeções dos modelos climáticos permitem a geração de cenários de clima no futuro, mas ainda não distinguem ou separam os efeitos da variabilidade natural de clima e da induzida pelo homem. Portanto, somente um maior conhecimento de ambos poderá apontar com maior exatidão qual o futuro do planeta e, em particular, do estado da Bahia. 


\section{Referências}

ARCINIEGAS, C. L. W. et al. Emissão de óxido nitroso da produção de soja no Cerrado brasileiro. In: ENCONTRO de Química Analítica Ambiental, VI, 2012, Londrina. Anais eletrônicos... Londrina:

Sociedade Brasileira de Química, 1990.

BAILEY, R. A. et al. Chemistry of the Environment,

2. ed. Nova York: Academic Press, 2002. 575p.

BITTENCOURT, A. C. S. P.; BRICHTA, A.; DI NAPOLI, E.

Alguns aspectos da sedimentação na Baía de Todos os Santos.

Revista Brasileira Geofísica. v. 6, n. 4, p. 246-263, 1976.

CIRANO, M.; LESSA, G. C. Oceanographic characteristics of Baía de Todos os Santos, Brazil. Revista Brasileira de Geofísica, v. 25, p. 363-387, 2007.

CRUTZEN, P. J. et al. $\mathrm{N}_{2} \mathrm{O}$ release from agro-bifuel production negates global warming reduction by replacing fossuel fuels.

Atmos. Chem. Phys. n. 7, p. 11191-11205, 2007

DIAS, P. L. S. et al. Public Policy, Mitigation and Adaptation to

Climate Change in South America. São Paulo: INPE. 2009.

EMANUEL, K. Increasing destructiveness of tropical cyclones over the past 30 years. Nature. v. 436, n. 7051, p. 686-688, ago. 2005.

EMBRAPA. Primeiro inventário brasileiro de emissões antrópicas de gases de efeito estufa. Relatórios de referência. Emissões de óxido nitroso $\left(\mathrm{N}_{2} \mathrm{O}\right)$ provenientes de solos agrícolas. Brasília: Ministério da Ciência e Tecnologia. 2006. 129p.

EVANGELISTA, $\mathrm{H}$. et al. Evidences linking ENSO and coral growth in the Southwestern-South Atlantic. Climate Dynamics, v. 29, p. 869-880, 2007.

GRAEDEL, T. E.; CRUTZEN, P. J. Atmosphere, climate and change. New York: Scientific American Library, 1995.

GUARÍN, R. R. Medidas de óxido nitroso $\left(\mathrm{N}_{2} \mathrm{O}\right)$ emitido por culturas de mamona e girassol para produção do agro diesel e potencial contribuição para as mudanças climáticas. 2010. 210f. Dissertação (Mestrado de Saúde, Ambiente, Trabalho) - Faculdade de Medicina, UFBA. Salvador, 2010.

IPCC - INTERGOVERNMENTAL PANEL ON CLIMATE.

FOURTH ASSESSMENT REPORT. AR4. IPCC 2007.

Disponível em : <http://www.ipcc.ch>

IPCC- INTERGOVERNMENTAL PANEL ON CLIMATE. FOURTH

ASSESSMENT IPCC AR4 SYR . In: PACHAURI, R. K; REISINGER, A.

Climate Change 2007: Synthesis Report. Contribution of 
Working Groups I, II and III to the Fourth Assessment Report of the Intergovernmental Panel on Climate Change. 2007.

KRUG, L. A. et al. Characterization of coral bleaching environments and their variation along the Bahia state coast, Brazil. International Journal of Remote Sensing, v. 33, p. 4059-4074, 2012.

LONDON CLIMATIC CHANGE PARTNERSHIP - LCCP .

Adapting to Climatic Change: Lessons for London. London: Greater London Authority. 2006.

LEÃO, Z. M. A. N.; KIKUCHI, R. K. P.; OLIVEIRA, M. D. M. Branqueamento de corais nos recifes da Bahia e sua relação com eventos de anomalias térmicas nas águas superficiais do oceano. Biota Neotrop. v. 8, n. 3, p. 69-82, 2008

LEITE, O. R. Evolução da Bahia de Todos os Santos, Revista do IFUFBA, 1995.

. Evolução geológica. In: Baía de Todos os Santos:

diagnóstico sócio-ambiental e subsídios para a gestão.

Salvador: Germen/UFBA-NIMA, 1997. p. 15-29.

MAGNAVITA, L. P.; DAVISON, I.; KUZNIR, N. J. Rifting, erosion and uplift history of the Reconcavo-Tucano-Jatobá Rift, Northeast Brazil. Tectonics, Washington, v. 13, n. 2, p. 367-388, 1994.

MARENGO, J. Mudanças Climáticas Globais e seus Efeitos sobre a Biodiversidade Caracterização do Clima Atual e Definição das Alterações Climáticas para o Território Brasileiro ao Longo do Século XXI. 2. ed. Brasília: Ministério do Meio Ambiente, 2007a. 213 p.

. Caracterização do Clima no século XX e Cenários no Brasil e na América do Sul para o Século XXI derivados dos Modelos de Clima do IPCC. Relatório n. 1. Brasília: Ministério do Meio Ambiente, 2007b. 181 p. . et al. Atlas de Cenários Climáticos Futuros do Brasil. Cachoeira Paulista - SP: CPTEC, INPE, 2007. 124p.

MARTIN, L. et al. Neotectonic movements on a passive continental margin: Salvador region, Brazil. Neotectonics, v. 1, p. 87-103, 1986.

. et al. Courbe de variations Du niveau relatif de La mer au cours dês 7. 000 dernières années sur um secteru homogène Du littoral brésilien (Nord de Salvador). In: International Symposium on Coastal Evolution in the Quaternary, 1978. São Paulo, Proceedings, 1979. p. 264-274.

MARTIN, L.; DOMINGUEZ, J. M. L.; BITTENCOURT, A. C. S. P. Climatic control of coastal erosion during a sea-level fall episode. An Acad. Bras. Ci., n. 70, p. 249-266, 1998. 
MARTIN, L.; DOMINGUEZ, J. M. L.; BITTENCOURT, A. C. S. P. Fluctuating Holocene sea levels is eastern and southeastern Brazil: evidence from a multiple fossil and geometric indicators. Journal of Coastal Research, v. 19, p. 101-124, 2003

RAMANA, M. V. et al. The direct observations of large aerosol radiative forcing in the Himalayan region. Geophys. Res. Lett. n. 31, 2004.

RAMANATHAN, V.; CARMICHAEL, G. Global and regional climate changes due to black carbon, Nature Geoscience, March, 2008.

SANTOS, N. A. C. et al. Association of annual dengue incidence in Northeast Brazil with global climate variability. In: Environmental Health 2011: Resseting Our Priorities, Salvador. Proceedings. Elsevier, 2011.

SCAFETTA, N. Empirical evidence for a celestial origin of the climate oscillations and its implications, Journal of Atmospheric and Solar-Terrestrial Physics, n. 72, p. 951-970, 2010.

. A shared frequency set between the historical mid-latitude aurora records and the global surface temperature, Journal of Atmospheric and Solar-Terrestrial Physics, n. 74, p. 145-163, 2012.

SILVA DIAS, P. L. et al. In: Conferência Regional sobre Mudanças Globais: América do Sul, III, São Paulo, 2007, Livro de resumos. São Paulo, USP, 2007.

SRIVASTAVA, A. K. et al. Black carbon aerosols over Manora Peak in the Indian Himalayan foothills: implications for climate forcing, Environ. Res. Lett. n. 7, p. 1-8. 2012

STERN, N. Review on the Economics of Climate Change. London: HM Treasury, 2006. Disponível em: <http://www.sternreview.org.uk.> Acesso em: 15 nov. 2012. STOZHKOV, Y. et al. Data on galactic cosmic fluxes according to the measurements in the atmosphere (1957-2006), preprint of Lebedev Physics Institute, Russian Academy of Sciences, Moscow, n. 14, p. 78, 2007.

TANAJURA, C. A. S; GENZ, F; ARAÚJO, H. A. Mudanças climáticas e recursos hídricos na Bahia: validação da simulação do clima presente do hadrm3p e comparação com os cenários A2 e B2 para 2070-2100. Revista Brasileira de Meteorologia, v. 25, n. 3, p. 345 - 358, 2010. TAVARES, T. M. et al. Luxos de Óxido Nitroso $\left(\mathrm{N}_{2} \mathrm{O}\right)$ e Dióxido de Carbono $\left(\mathrm{CO}_{2}\right)$ emitido por culturas de mamona e girassol para produção de agrodiesel. In: FAPESB. Relatório do Projeto Inovações no Semiárido, Edital 006/2007. Salvador: FAPESB, 2012. p. 1-6. 